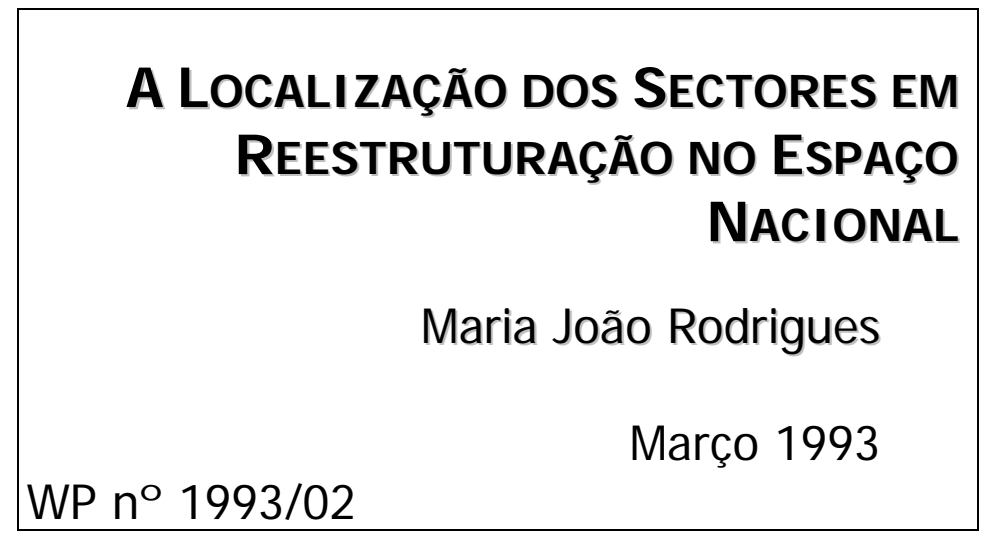

DOCUMENTO DE TRABALHO WORKING PAPER 


\title{
A Localização dos Sectores em Reestruturação no Espaço Nacional
}

\author{
Maria J oão Rodrigues \\ WP $93 / 02$ \\ Março de 1993
}

\section{Índice}

Introdução 1

1. Objectivo 1

2.Metodologia 1

3. Plano de trabalho efectuado 3

1. Identificação dos sectores mais propensos a reestruturação 4

2. A localização dos sectores em reestruturação no espaço nacional: análise global

2.1. As características gerais da localização dos sectores em reestruturação 5

2.2. Análise tipológica da localização dos sectores em reestruturação 6

2.3. Análise da sensibilidade dos concelhos ao conjunto das

reestruturações sectoriais 


\section{Introdução}

\section{Objectivo}

Esta comunicação insere-se na construção de um Observatório que, através da análise de diferentes fontes estatísticas, permita antecipar, detectar e acompanhar os processos de reestruturação produtiva e as suas repercussões no emprego a nível regional, no sentido de apoiar as funções de diagnóstico, concepção e implementação de políticas a cargo do IEFP e, mais em geral, do Ministério do Emprego e Segurança Social. Este trabalho visa produzir um conjunto de indicadores de prevenção, acompanhamento e avaliação e ainda a sua respectiva expressão cartográfica, no sentido de facilitar a sua visualização no conjunto do território nacional.

A montagem de um Observatório com este objectivo é de grande relevância num período em que os processos de reestruturação tenderão a acelerar-se e a multiplicar-se por efeito quer da crescente integração no espaço europeu, quer das mutações tecnológicas em curso. Ao aumentar a capacidade de antecipação desses processos, este Observatório reforça a possibilidade de lançamento de políticas preventivas que permitirão minorar os custos sociais das reestruturações, muitas vezes inevitáveis ou mesmo incontornáveis. Por outro lado, ao garantir uma caracterização mais precisa desses processos e das novas dinâmicas de emprego e de formação que eles geram, este Observatório cria também um suporte para a avaliação e a correcção das políticas neles envolvidas. Finalmente, toda esta iniciativa poderá, de algum modo, contribuir para a organização progressiva, ao nível regional, de observatórios de bacias de emprego susceptíveis de apoiar a actividade dos Centros de Emprego.

\section{Metodologia}

Este trabalho, ao visar não só o acompanhamento mas a antecipação, pressupõe a utilização de uma metodologia prospectiva. Um primeiro levantamento da bibliografia disponível ao nível nacional e internacional tanto sobre metodologias de prospectiva como sobre modelização em economia regional (v. Bibliografia em anexo), não nos tendo dado resposta directa a este problema, conduziu-nos a conceber uma metodologia específica para Ihe responder. Esta metodologia, a ser afinada e corrigida à medida que for sendo aplicada, compõe-se das seguintes etapas:

\section{1를 ETA}

Identificação dos sectores mais propensos a reestruturações e caracterização das opções estratégicas básicas que aí estarão em jogo, na medida em que elas se traduzam por diferentes tipos de reestruturação (as incidências sobre o emprego e a formação podem ser muito diferentes consoante o tipo de reestruturação em causa). 
Método: Aproveitamento e exploração de trabalhos de síntese e prospectiva já existentes, relativos aos impactes quer do mercado interno europeu, quer da mudança tecnológica.

\section{2를 EA}

Determinação da localização regional destes sectores, permitindo assim delimitar os segmentos do tecido produtivo mais relevantes do ponto de vista do impacte das reestruturações no emprego (um segmento é-nos dado pelo cruzamento sector/região).

Método: Exploração de uma matriz de emprego, cruzando sectores com o maior grau de desagregação possível e concelhos (Fonte: MESS, Quadros de Pessoal). Construção e análise de indicadores de localização e da sua representação cartográfica.

\section{3를 EA}

Caracterização dos segmentos mais sensíveis a reestruturações com vista a avaliação do impacte destas no emprego, tendo em conta que as reestruturações se traduzem por movimentos de afastamento, de reconversão interna e de recrutamento de trabalhadores

Método: Exploração de informação sobre a estrutura do emprego relativa ao tipo de empresa, qualificação, profissão, sexo, idade, habilitações escolares (Fonte: MESS, Quadros de Pessoal), e ainda da informação existente sobre fluxos de entradas e saídas de trabalhadores. Construção e análise de indicadores e da sua representação cartográfica.

\section{ETAPA}

Caracterização das regiões mais sensíveis a reestruturações com vista à avaliação do impacto destas no emprego (essas regiões poderão ser delimitadas a partir das bacias de emprego de implantação dos segmentos identificados na fase anterior).

Método: Exploração de informação sobre Pessoal)

a/ a estrutura sectorial do emprego nestas regiões (Fonte: MESS, Quadros de

b/ a composição da população residente nessas regiões em termos de idade, sexo, habilitações escolares, condição perante o trabalho, situação na profissão e profissão, e ainda a composição dos fluxos migratórios (Fonte: INE, Recenceamentos da População)

c/ a composição do desemprego registado e do movimento de pedidos e ofertas de emprego (Fonte: IEFP) com vista à construção e análise de indicadores e à sua 


\section{ETAPA}

Avaliação das possibilidades de promoção do emprego e de criação de alternativas para os postos de trabalho suprimidos nas regiões identificadas como mais sensíveis.

Método: exploração da informação sobre

a/ a estrutura de implantação de novas infraestruturas, novas empresas, novos investimentos (Fontes: INE, IAPMEI, IEFP, DGDR-QCA)

b/ a estrutura de saídas do sistema escolar (Fonte: GEP-ME)

c/ o grau de execução dos objectivos fixados para as medidas de política de emprego e de formação (Fonte: IEFP)

com vista à construção de indicadores e à sua representação cartográfica.

A presente comunicação apresenta os resultados obtidos ao longo das etapas 1 , 2, e parte da 4, sendo que a terceira etapa está já em curso de elaboração.

\section{Plano de Trabalho Efectuado}

1. Definição de uma metodologia global para a construção progressiva do Observatório

2. Identificação dos sectores mais propensos a reestruturações com base na bibliografia disponível

3. Estudo crítico das fontes: caracterização dos circuitos de produção da informação e das variáveis segundo os erros, omissões e segredo estatístico

4. Definição do plano de análise e selecção metodológica: escalas, níveis de agregação, técnicas de tratamento de dados, sistema de representação cartográfica, construção de software próprio

5. Preparação dos dados: transcrição, conversão de formatos, compatibilizações devido a erros e segredo estatístico, agregações e construção de uma base de dados operativa para cálculo de indicadores

6. Cálculo dos indicadores e produção de mapas de trabalho

7. Interpretação e afinação dos resultados

8. Preparação da publicação e plano editorial: selecção dos mapas, diagramas, indicadores e tabelas e inserção dos textos de interpretação

9. Produção gráfica: composição, maquetagem e impressão 


\section{Identificação dos Sectores mais propensos a reestruturações}

Para a construção deste Observatório trabalhámos com uma definição lata de sector em reestruturação. Contrariamente a certo entendimento restrito bastante corrente, um sector em reestruturação não é só o sector que está na perspectiva de perder uma parte substancial do seu volume de emprego. Em termos mais gerais, é todo o sector que, por razões de alterações de mercado, tecnológicas e/ou organizativas venha a gerar fluxos significativos de afastamento, reconversão ou recrutamento de trabalhadores, independentemente do seu volume de emprego diminuir, aumentar ou manter-se estável. É que, do ponto de vista das políticas de emprego e de formação, são também estes fluxos e não apenas a evolução do volume de emprego que são relevantes.

Se aceitarmos este pressuposto trata-se portanto de identificar todos os sectores mais propensos à reestruturação no caso concreto da economia portuguesa, tendo em conta que o seu contexto actual é particularmente marcado por dois importantes processos propulsores de reestruturações:

- a alteração e a intensificação das pressões concorrenciais decorrentes da construção da União Económica e Monetária e amplificadas pela emergência de um Espaço Económico Europeu;

- a rápida difusão de um novo paradigma técnico-económico e das mudanças organizacionais que lhe podem estar associadas.

Foi portanto a partir do cruzamento destes dois critérios que seleccionámos os sectores mais propensos à reestruturação em Portugal no âmbito da indústria transformadora e do terciário. Por razões que se prendem com as características muito particulares do funcionamento económico e da gestão do emprego no sector primário, não o contemplamos, de momento, na nossa análise.

A síntese de partida utilizada para a selecção destes sectores está contida num livro publicado por um membro desta equipa (Maria João Rodrigues, Competitividade e Recursos Humanos - dilemas de Portugal na construção europeia, Lisboa, Publicações Dom Quixote, 1991), tendo depois sido adaptada para as necessidades deste nosso trabalho da forma que se segue. 


\section{A localização dos sectores em reestruturação no espaço nacional: análise global}

De acordo com o exposto na Introdução, a $2^{\underline{a}}$ etapa deste projecto destina-se a apresentar a localização do emprego de 40 Sectores, a maioria dos quais particularmente propensos a reestruturações (e que passaremos a designar simplesmente por Sectores em Reestruturação). Por localização deve entender-se a distribuição espacial do emprego de cada sector no território de Portugal Continental.

Este estudo de localização visa fundamentalmente identificar:

- os concelhos mais relevantes do ponto de vista das políticas de emprego e formação profissional, se considerarmos simultaneamente 0 volume e o peso relativo que cada sector em reestruturação neles regista;

- os concelhos especialmente sensíveis às reestruturações de certos sectores.

\subsection{As Caracteristicas Gerais da Localização dos Sectores em Reestruturação}

Os sectores mais propensos a reestruturações correspondem a um valor muito considerável do total de emprego no Continente (medido sob a forma de pessoal ao serviço nas empresas de mais de 10 trabalhadores): 46,91\% do total desse emprego ou seja, em números absolutos, 988795 trabalhadores, sendo que a média de trabalhadores por concelho é de 3 595,62 (V.quadros G-1, 4 e 7).

Este grupo de Sectores está presente em todos os 275 concelhos do Continente com um peso relativo médio no emprego de cada concelho de $46,91 \%$, ainda que uma certa variabilidade (desvio padrão de 19.87). Esta grande dispersão é também comprovada pelo baixo valor do índice de concentração (I.CNC=I.CNC/C=0,1574) do peso relativo destes sectores no emprego dos vários concelhos.

No entanto, o quadro 5 revela que $31,75 \%$ destes trabalhadores (=313 899) estão localizados em apenas três concelhos:

\begin{tabular}{|ll|ll|ll|}
\hline Lisboa & 185566 & Porto & 82437 & Guimarães & 45896 \\
\hline
\end{tabular}

Revela também que mais $20,80 \%(=205630)$ do total dos trabalhadores considerados se encontram em nove concelhos apenas:

\begin{tabular}{|c|c|c|}
\hline V.N.Gaia & 25997 & Matosinhos \\
\hline
\end{tabular}




\begin{tabular}{|ll|ll|ll|}
\hline S.Tirso & 29221 & VN.Famalicão & 31009 & Barcelos & 19902 \\
\hline Braga & 19029 & Coimbra & 18200 & Loures & 21735 \\
\hline
\end{tabular}

(para estes valores absolutos V.quadro 1 e mapa 1).

Outras conclusões sobre os concelhos onde poderão surgir maiores problemas ressaltam da análise em termos relativos. O quadro 8 e o mapa 2 mostram que são 13 os concelhos em que o peso relativo dos sectores em reestruturação é muito grande $(=>69,42 \%=<93,7 \%)$. Trata-se dos seguintes concelhos:

\begin{tabular}{|ll|ll|ll|}
\hline Esposende & $76,28 \%$ & Fafe & 77,18 & Belmonte & $81,21 \%$ \\
\hline Barcelos & $79,47 \%$ & Felgueiras & $81,45 \%$ & Guimarães & 72,27 \\
\hline Gouveia & $79,35 \%$ & St $\stackrel{\text { o.Tirso }}{73,52 \%}$ & Covilhã & $73,49 \%$ \\
\hline Cast.Pera & $93,71 \%$ & Manteigas & $78,53 \%$ & Seia & $69,83 \%$ \\
\hline Boticas & $75,95 \%$ & & & & \\
\hline
\end{tabular}

Além disto, os concelhos em que o peso relativo destes sectores é ainda francamente grande $(>55,39 \%<69,42 \%)$ são 15 :

\begin{tabular}{|ll|ll|ll|}
\hline VN.Famalicão & $68,10 \%$ & S.J.Madeira & $66,32 \%$ & Portimão & $57,48 \%$ \\
\hline P.Lanhoso & $59,14 \%$ & Mangualde & $56,86 \%$ & Albufeira & $58,14 \%$ \\
\hline Lousada & $69,33 \%$ & Alcobaça & $57,81 \%$ & V.Bispo & $56,92 \%$ \\
\hline V.Conde & $58,02 \%$ & Azambuja & $61,97 \%$ & Aljezur & $56,49 \%$ \\
\hline O.Azemeis & $59,81 \%$ & Moita & $62,74 \%$ & V.R.S.António & $56,03 \%$ \\
\hline
\end{tabular}

\subsection{Análise Tipológica da Localização dos Sectores em Reestruturação}

A nossa análise irá mais longe se dispusermos de uma tipologia de localização destes sectores que cruze o volume e o peso relativo que eles têm no emprego total de cada concelho, no sentido de destacar os concelhos mais relevantes deste duplo ponto de vista. Para este efeito, construímos uma tipologia que apresenta as seguintes classes:

\footnotetext{
gG - Concelho com grande volume de emprego e muito especializado nos sectores em reestruturação;

mG - Concelho com volume médio de emprego e muito especializado nesses sectores;

pG - Concelho com pequeno volume de emprego e muito especializado nesses sectores;

gM - Concelho com grande volume de emprego e medianamente especializado nesses sectores;

mM - Concelho com volume médio de emprego e medianamente especializado nesses sectores;
} 


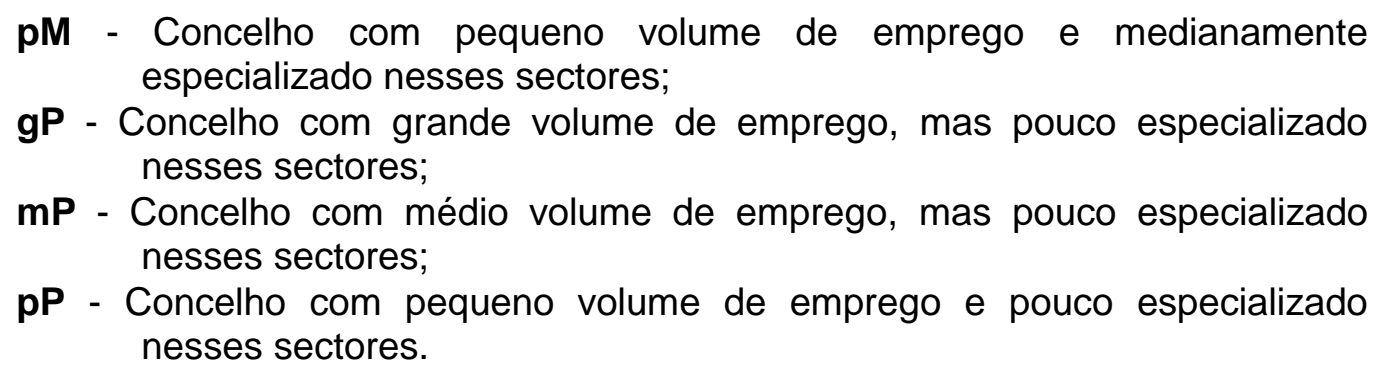

Consideraremos que os concelhos que devem merecer a primeira prioridade no acompanhamento por políticas de emprego, formação profissional e desenvolvimento regional são os designados por gG. A segunda prioridade deveria ser atribuída aos concelhos designados por $\mathbf{m G}$ e gM. Os concelhos classificados como pG, mM e gP serão encarados como terceira prioridade, já que os fluxos de trabalhadores afastados pelos sectores em reestruturação poderão, em princípio, ser mais facilmente absorvidos pela bacia local de emprego. Por fim os concelhos tipo $\mathbf{m P}$ e pM serão considerados pouco relevantes e os concelhos do tipo pP serão tidos por não relevantes.

O quadro 6 e o mapa 4 apresentam justamente a distribuição dos concelhos e dos trabalhadores dos sectores em reestruturação segundo estas classes tipológicas. Deles se retira nomeadamente que:

- Os concelhos da classe gG (1 ${ }^{\text {a }}$.prioridade) são $5,5 \%$ do total dos concelhos e correspondem a $35,4 \%$ dos trabalhadores considerados;

- Os concelhos da classe mG (2ª .prioridade) são $6,5 \%$ do total dos concelhos e $7,7 \%$ dos trabalhadores considerados.

- Os concelhos da classe gM (2 ${ }^{\mathrm{a}}$. prioridade) são $3,3 \%$ do total dos concelhos e $30,1 \%$ dos trabalhadores considerados;

- Os concelhos da classe pG são 4,4\% dos concelhos e correspondem apenas a $1,1 \%$ dos trabalhadores considerados.

Uma outra ilação que se pode retirar é que $57,5 \%$ dos concelhos estão na classe pP, apresentando portanto pouca relevância e preocupação quanto ao impacto das reestruturações, muito embora lhe correspondam apenas $5,3 \%$ do total de trabalhadores considerados. Estes concelhos estão integrados na zona preenchida com a mancha de tipo -R-A no mapa 4, o qual representa graficamente a classificação tipológica a que nos reportamos, e que resulta do cruzamento dos mapas 1 e 2 . Por sua vez, a listagem nominal destes concelhos pode ser encontrada na $1^{a}$.coluna (pP (A/-R)) do quadro 10.

Em contrapartida, vale a pena analisar mais em pormenor quais os concelhos que se encontram nas classes tipológicas que exigem mais atenção quanto ao impacto das reestruturações. Partiremos do princípio de que essas classes são as designadas por $\mathbf{g G}, \mathbf{m G}$ e $\mathbf{g} \mathbf{M}$ ou seja, as regiões consideradas de $1^{\mathrm{a}}$. e $2^{\text {a }}$. prioridade.

Ora, segundo a classificação dos concelhos apresentada no quadro 3 e reorganizada no quadro 10 , os concelhos de $1^{a}$. prioridade no que respeita ao 
conjuntos dos sectores mais propensos a reestruturação são (V.também, no mapa 4, a zona tingida na côr $+\mathbf{R} / \mathbf{+ A}$ ):

\begin{tabular}{|l|l|}
\hline \multicolumn{1}{|c|}{ DISTRITO } & \multicolumn{1}{c|}{ CONCELHOS } \\
\hline Braga & Barcelos, Braga, Guimarães e Famalicão \\
Porto & Felgueiras, Maia, Porto, S. Tirso e Vila do Conde \\
Aveiro & Oliveira de Azemeis e S.João da Madeira \\
Coimbra & Coimbra \\
Castelo Branco & Covilhã \\
Lisboa & Cascais \\
Setubal & Almada \\
\hline
\end{tabular}

Quanto aos concelhos de $2^{\mathrm{a}}$. prioridade (V. no mapa 4, a zona tingida na côr $\mathbf{A} / \mathbf{+} \mathbf{R}$ e + $\mathbf{A} / \mathbf{R})$ :

\begin{tabular}{|l|l|}
\hline \multicolumn{1}{|c|}{ DISTRITO } & \multicolumn{1}{c|}{ CONCELHOS } \\
\hline Viana do Castelo & Viana do Castelo \\
Braga & Fafe e Esposende \\
Porto & Matosinhos, V. N. Gaia, Lousada e Povoa do Varzim \\
Aveiro & Aveiro e Estarreja \\
Viseu & Mangualde \\
Guarda & Gouveia, Guarda e Seia \\
Leiria & Alcobaça, Caldas da Rainha e Peniche \\
Castelo Branco & Belmonte \\
Lisboa & Lisboa, Oeiras, Amadora e Azambuja \\
Setubal & Seixal, Setúbal e Moita \\
Faro & Albufeira, Loulé e Portimão \\
\hline
\end{tabular}

\subsection{Análise da Sensibilidade dos Concelhos ao Conjunto das Reestruturações Sectoriais}

Esta identificação dos concelhos ditos de 1a. e 2a . prioridade - que deverão ser seguidos com o maior cuidado, dada a amplitude das reestruturações do emprego que aí são previsíveis - deve ser completada por uma análise da sensibilidade dos concelhos às reestruturações. Esta avaliação ex-ante da sensibilidade baseia-se na "importância real" que os sectores mais propensos a reestruturações têm em cada concelho, medindo-se esta importância por uma escala externa e pré definida de acordo com escalões com significado próprio e de leitura imediata. Esses escalões são os seguintes: (V. quadro 9): 


\begin{tabular}{|c|c|}
\hline $\begin{array}{ll}\text { Concelhos } & \text { de } \\
\text { sensibilidade } & \end{array}$ & $\begin{array}{ll}\text { Pessoal ao serviço } & \text { nos } \\
\text { sectores } & \text { em } \\
\text { reestruturação } & \\
\end{array}$ \\
\hline $\begin{array}{l}\text { Grau } 1 \\
\text { Grau } 2 \\
\text { Grau } 3 \\
\text { Grau } 4 \\
\text { Grau } 5 \\
\text { Grau } 6\end{array}$ & $\begin{aligned} 0 & <5 \% \\
5 & <17 \% \\
17 & <33 \% \\
33 & <50 \% \\
50 & <67 \% \\
67= & <100 \%\end{aligned}$ \\
\hline
\end{tabular}

Quais são pois os concelhos com sensibilidade de grau 6 e 5, ou seja, mais vulneráveis às reestruturações devido ao peso desses sectores aí ultrapassar $50 \%$ do total de emprego (pessoal ao serviço)? Ou, dito de outro modo, quais os concelhos que exigem políticas activas de antecipação dos efeitos das reestruturações?

Estes concelhos podem ser identificados a partir do quadro 2 e do mapa 3, como se segue:

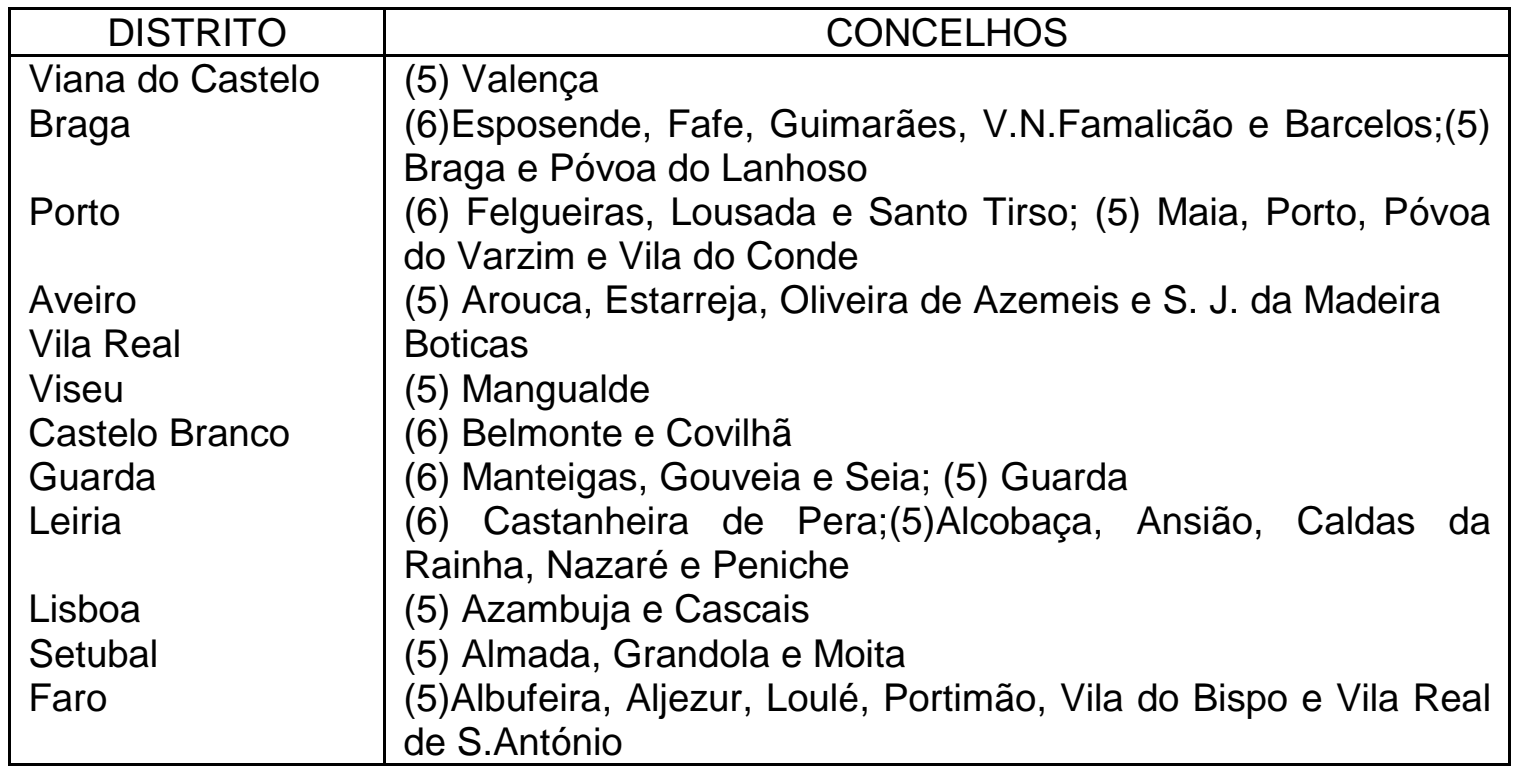

Se quisermos indagar quais os sectores que mais explicam a sensibilidade à reestruturação destes concelhos, teremos de recorrer ao quadro G-3. Por exemplo se para Barcelos são o Vestuário e as Malhas, para V.N.Famalicão é o Algodão, para Albufeira e Portimão, é o Comércio a retalho, para Alcobaça é a Cerâmica, para Azambuja o Automóvel e para Boticas é o de Refrigerantes e águas minerais. 
Este quadro pode também ser lido para responder a uma questão: quais os concelhos mais sensíveis à reestruturação dos 33 sectores considerados nesta análise? Podemos constatar que os sectores que geram uma sensibilidade relevante (de grau igual ou superior a 3) são uma lista mais restrita de 15 sectores: vestuário, lanifícios, algodão, malhas, calçado, comércio a retalho, comércio por grosso, vidro, cerâmica, conservas de peixe, panificação, refrigerantes e águas minerais, químicos (para indústria e agricultura) siderurgia e instituições de crédito.

Se quisermos aprofundar mais a análise, no sentido de abranger mais sectores e captar mais concelhos ainda que menos sensíveis às reestruturações, poderemos examinar a coluna com o grau 2 do Quadro G-3 mas teremos de apoiar-nos também nas monografias de sectores apresentados no Capítulo 4.

As monografias sectoriais que apresentamos nos Volumes seguintes podem ser consultadas uma a uma consoante as necessidades e interesses do leitor e contêm, para cada um dos sectores, todos os elementos que acabamos de comentar para o conjunto dos sectores mais propensos à reestruturação.

Para uma consulta sintética e incisiva de toda a informação disponível, o leitor poderá começar por observar os 4 mapas de cada monografia. Esses mapas servem para responder basicamente às seguintes questões:

Mapa 1 - Onde (em que concelhos) estão os maiores volumes de emprego (pessoal ao serviço)? Qual o volume de emprego desse sector que está localizado em cada concelho?

Mapa 2 - Quais os concelhos mais especializados no sector X? Qual o peso relativo desse sector em cada concelho, classificado através de um escala interna constituída a partir das características desse sector?

Mapa 3 - Quais os concelhos particularmente sensíveis à reestruturação no sector $\mathrm{X}$, devido ao importante peso relativo de que este dispõe no emprego total (total de pessoal ao serviço) do concelho? Qual o grau de sensibilidade de cada concelho? Qual o peso relativo desse sector em cada concelho, classificado através de uma escala externa, independentemente das características desse sector?

Mapa 4 - Quais os concelhos mais relevantes para o sector $X$ se cruzarmos os critérios da coluna de emprego e de peso relativo desse sector em cada concelho? Qual o grau de prioridade a atribuir no acompanhamento de cada concelho numa situação de reestruturação desse sector?

O Mapa 4 sintetiza pois a informação contida nos mapas 1 e 2 de acordo com a simbologia gráfica explicada na legenda. 
Consideram-se

$\begin{array}{ll}\text { Regiões de } & \text { Tingidas com a côr } \\ \text { 1‥ prioridade } & +A /+R \\ 2^{a} \text {. prioridade } & =A /+R \text { e }+A /=R \\ 3^{a} \text {. prioridade } & +A /-R,=A /=R \text { e }-A /+R \\ \text { pouco relevantes } & -A /=R \text { e }=A /-R \\ \text { não relevantes } & -A /-R\end{array}$

Para um conhecimento das principais características de cada sector convirá no entanto não ficar pelos mapas e ler o comentário que é feito a toda a série de outputs estatísticos. Finalmente, para uma análise mais pormenorizada de cada sector poderse-á ainda consultar toda uma série de outputs estatísticos integrada na parte final de cada monografia. A parte que se segue tem pois três níveis de leitura e de aprofundamento: mapas, texto e outputs estatísticos.

Lembramos por fim que estas monografias se reportam não só aos 33 sectores seleccionados como mais propensos à reestruturação, mas também a mais 7 sectores considerados relevantes do ponto vista da dinâmica de criação e supressão de emprego em Portugal.

O quadro G-4 resume para os 40 sectores de estudo um dos aspectos mais importantes das análises monográficas: identificar os concelhos ditos de $1^{\underline{a}}$. e $2^{\underline{a}}$. prioridade de intervenção para cada sector e estimar o volume de emprego aí envolvido.

Este quadro permite pois perspectivar as prioridades regionais a ter em conta quando se implementam políticas sectoriais. 